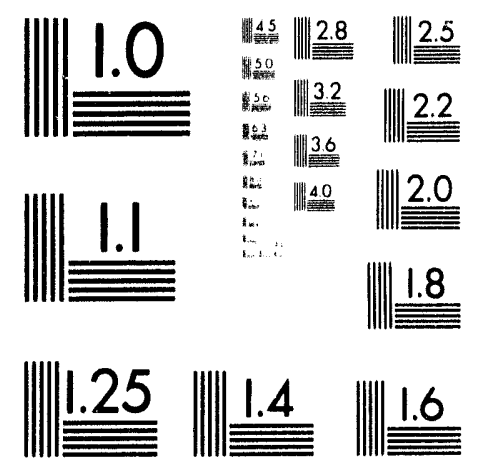



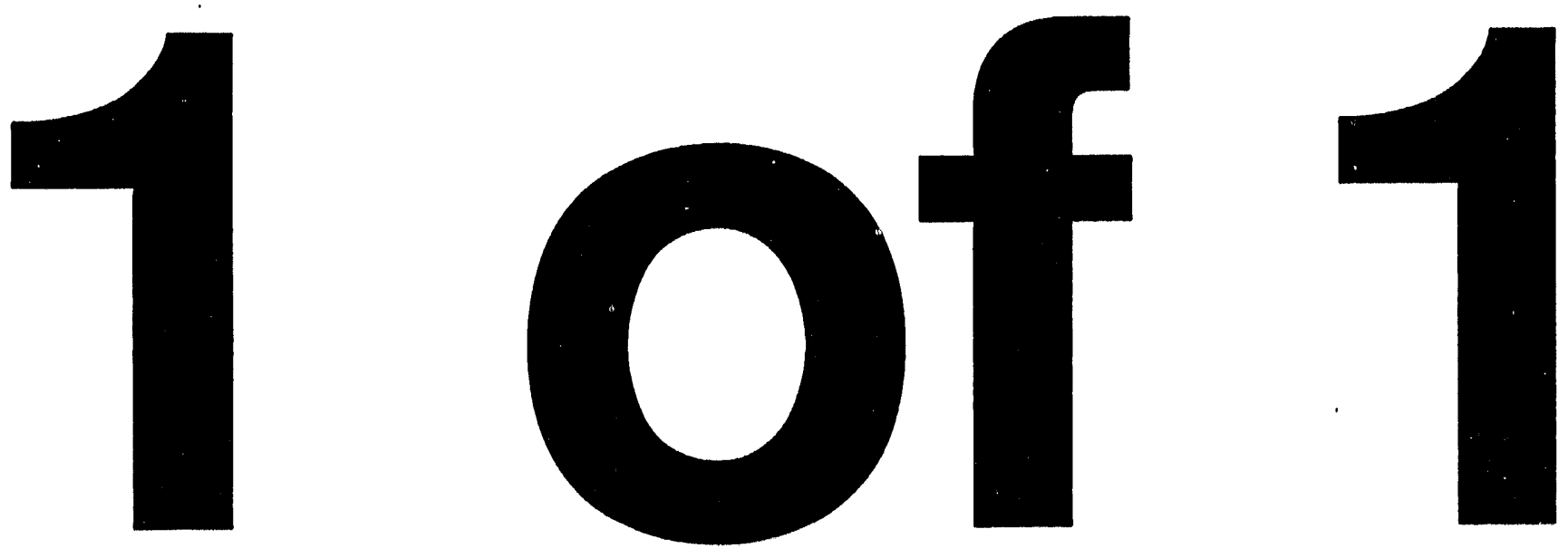


$$
\begin{aligned}
& \text { ANH/CMT/CP-39342 } \\
& \text { CD. } 931043 \cdots 2
\end{aligned}
$$

\title{
WASTE REMEDIATION USING IN SITU \\ MAGNETICALLY ASSISTED CHEMICAL SEPARATION
}

L. Nuñez, B. A. Buchholz, and G. F. Vandegrift

Chemical Technology Division

Argonne National Laboratory

9700 S. Cass Ave

Argonne Illinois, 60439-4837

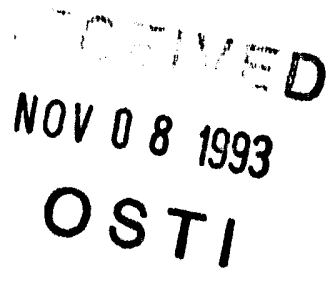

\begin{abstract}
The magnetically assisted chemical separation process (MACS) combines the selective and efficient separation afforded by chemical sorption with the magnetic recovery of ferromagnetic particles. This process is being developed for treating the underground storage tanks at Hanford. These waste streams contain cesium, strontium, and transuranics (TRU) that must be removed before this waste can be disposed of as grout. The separation process uses magnetic particles coated with either 1) a selective ion exchange material or an organic extractantcontaining solvent (for cesium and strontium removal) or 2) solvents for selective separation of TRU elements (e.g., TRUEX process). These coatings, by their chemical nature, selectively separate the contaminants onto the particles, which can then be recovered from the tank using a magnet. Once the particles are removed, the contaminants can either be left on the loaded particles and added to the glass feed slurry or stripped into a small volume of solution so that the extracting particles can be reused. The status of the chemistry and separation process is discussed in this paper.
\end{abstract}

\section{INTRODUCTION}

The Efficient Separation Processes Integrated Program (ESPIP) has been created by the U.S. Department of Energy (DOE) to develop and integrate processes for remediation efforts. Under the program, promising technologies are developed for application to the separation and concentration of radionuclides and hazardous components.

Among the major waste problems is the Hanford underground tank site that currently has many underground storage tanks containing high-level waste (HLW). These tanks have a wide variety of problems. Processing of nuclear materials for the national defense over the last 40 years has left the tanks filled with highly active nuclear waste, and some of them pose immediate safety concerns. The tank wastes pose particularly complex problems because they are inhomogeneous: the tank can be categorized in these type's; saltcake, supernatant, and sludge. The sludge is the most difficult to treat because of its complexity and multiple phases.

The major radionuclides of concern are ${ }^{137} \mathrm{Cs},{ }^{90} \mathrm{Sr}$, and, TRU elements. These contaminants must be removed before the bulk of the waste can be disposed of as low level waste. The use of current technologies to process these tank wastes would present two major problems. First, the quantity of glass produced would exceed Hanford's goal, set under its "Clean Option 
Strategy" for pretreatment, of producing fewer than 1000 canisters of glass to contain these radionuclides for deposit in a deep geologic repository (1). Second, a rather complex pretreatment facility is being planned to meet clean option goals, but this facility is still decades away from completion. Means to begin early processing of tank wastes are needed much sooner to start process of final disposal for the wastes. The complexity of the regulator issues can delay cleanup when such activities are involved. The problems could be addressed by the development of modular processes and compact operating units that provide adequate decontamination without requiring the construction of complex facilities.

One such compact processing unit is the MACS process. The MACS process combines the selective and efficient separation afforded by chemical sorption with magnetic recovery of the extractant. In the MACS program, ANL is developing in-tank, or near-tank processes for removal of contaminants from solution. This technology is promising because radionuclides are separated from waste streams uy a simple, compact, cost-effective process that does not produce large secondary waste streams.

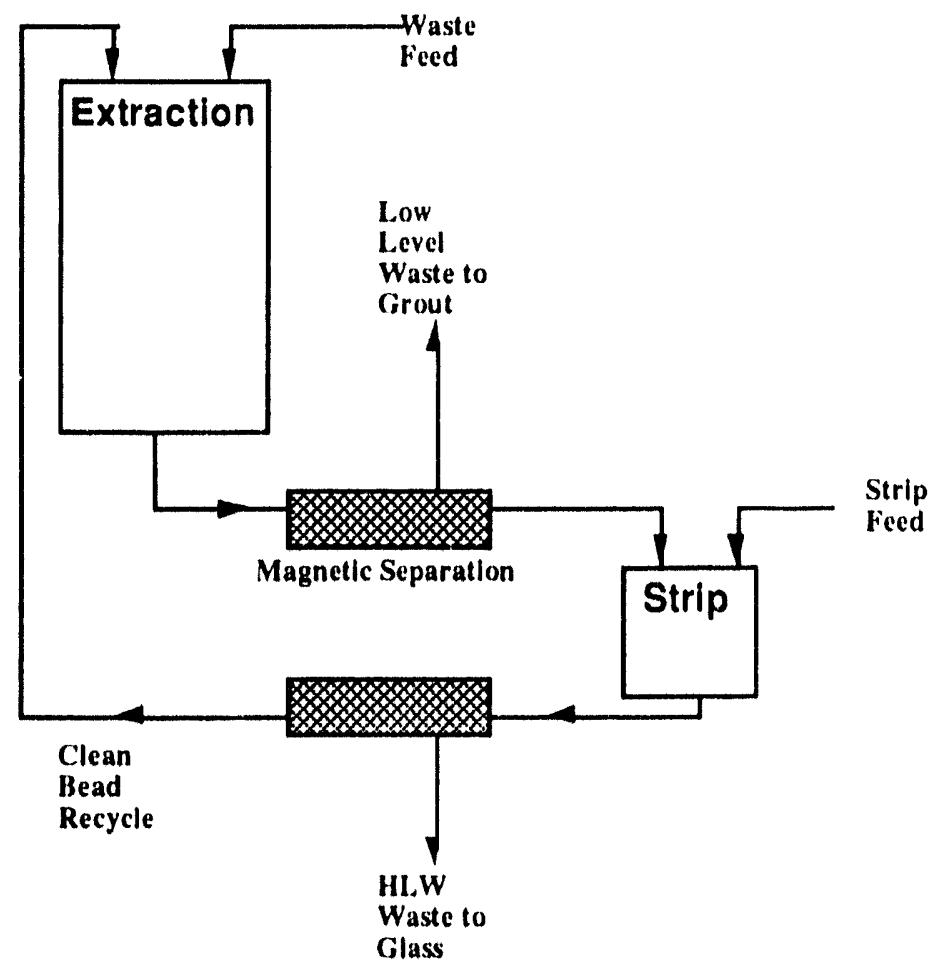

Fig. 1. Concept Diagram of MACS Process

The MACS process is still in the developmental stage. Figure 1 shows a diagram of the MACS concept. In this concept, the dissolved sludge stream is added to a treatment tank. (This 
tank can also be used for the stripping stage.) Magnetic particles coated with extractants are added to the treatment tank to separate the TRU and/or other contaminants from the dissolved sludge. To maintain particle suspension, the tank contents can be mixed by mechanical stirring or other methods. After extraction, the particles are magnetically separated by one of three methods: 1) placing a magnetic field around the treatment tank, 2) pumping the solution through a magnetic filter, or 3) introducing a magnet inside the tank. The waste solution now decontaminated is withdrawn and can be sent to grout. The TRU-loaded particles are left in the tank for stripping with a smaller volume of liquid (compared to the original feed volume). The TRU contaminants are separated from the magnetic particles and sent to glass, while the particles are recycled for further extraction.

The MACS process is intended to 1) reduce the complexity of equipment, compared with solvent extraction and ion exchange and 2) facilitate scale-up because of its simplicity. One of the Hanford tank wastes that the MACS process can successfully treat is the waste from the neutralized Plutonium Finishing Plant (PFP) at Hanford. The Hanford Site currently has many tanks filled with PFP wastes, with each tank containing approximately one million gallons.

In this report, we focus only on the process development of the TRU separation process. The greatest benefit of the technology is that radionuclides are separated from waste streams by a simple, compact, and cost-effective process that does not produce large secondary waste streams.

\section{TRU REMOVAL FROM DISSOLVED SLUDGE}

Argonne is developing a magnetic particle coated with octyl(phenyl)-N, N diisobutylcarbamoylniethylphosphine oxide (CMPO), the solvent currently used in the TRUEX process (3). These particles are designed to be used to remove TRU elements from solutions generated by dissolving Hanford tank sludge. For several reasons, a CMPO-based solvent is a natural choice for the first solvent extraction system (2) to be sorbed with magnetic particles: CMPO has high selectivity and extracting power for actinides; a vast background of data, experience, and understanding is available on the TRUEX solvent and process (3); and this solvent can be absorbed onto a solid particle (Elchrom has used a CMPO solvent to commercially prepare chromatographic material).

Because the coated particles are intended to be used in a batch mode, distribution ratios and solvent loading of TRU elements should be as high as possible, but mass transport should not limit the effectiveness of separation. To achieve these two frequently opposing objectives, the composition of the solvent coating will need to be optimized. Increasing the concentration of CMPO will increase distribution ratios and loading; however, it is also likely to increase solvent viscosity and its propensity to separate into two phases, lowering mass transfer. In the standard 
tank can also be used for the stripping stage.) Magnetic particles coated with extractants are added to the treatment tank to separate the TRU and/or other contaminants from the dissolved sludge. To maintain particle suspension, the tank contents can be mixed by mechanical stirring or other methods. After extraction, the particles are magnetically separated by one of three methods: 1) placing a magnetic field around the treatment tank, 2) pumping the solution through a magnetic filter, or 3) introducing a magnet inside the tank. The waste solution now decontaminated is withdrawn and can be sent to grout. The TRU-loaded particles are left in the tank for stripping with a smaller volume of liquid (compared to the original feed volume). The TRU containinants are separated from the magnetic particles and sent to glass, while the particles are recycled for further extraction.

The MACS process is intended to 1) reduce the complexity of equipment, compared with solvent extraction and ion exchange and 2) facilitate scale-up because of its simplicity. One of the Hanford tank wastes that the MACS process can successfully treat is the waste from the neutralized Plutonium Finishing Plant (PFP) at Hanford. The Hanford Site currently has many tanks filled with PFP wastes, with each tank containing approximately one million gallons.

In this report, we focus only on the process development of the TRU separation process. The greatest benefit of the technology is that radionuclides are separated from waste streams by a simple, compact, and cost-effective process that does not produce large secondary waste streams.

\section{TRU REMOVAL FROM DISSOLVED SLUDGE}

Argonne is developing a magnetic particle coated with octyl(phenyl)-N, N diisobutylcarbamoylmethylphosphine oxide (CMPO), the solvent currently used in the TRUEX process 3). These particles are designed to be used to remove TRU elements from solutions generated by dissolviig Hanford tank sludge. For several reasons, a CMPO-based solvent is a natural choice for the first solvent extraction system (2) to be sorbed with magnetic particles: CMPO has high selectivity and extracting power for actinides; a vast background of data, experience, and understanding is available on the TRUEX solvent and process (3); and this solvent can be absorbed onto a solid particle (Elchrom has used a CMPO solvent to commercially prepare chromatographic material).

Because the coated particles are intended to be used in a batch mode, distribution ratios and solvent loading of TRU elements should be as high as po'ssible, but mass transport should not limit the effectiveness of separation. To achieve these two frequently opposing objectives, the composition of the solvent coating will need to be optimized. Increasing the concentration of CMPO will increase distribution ratios and loading; however, it is also likely to increase solvent viscosity and its propensity to separate into two phases, lowering mass transfer. In the standard 
TRUEX solvent, 1.4M tributyl phosphate (TBP) acts as a solvent modifier. For this application, it is being used as the diluent.

Magnetic particles are available from several commercial suppliers. These particles come in a variety of sizes and magnetic properties, with different polymeric coatings. On the basis of our own experience, the literature, and discussions with the suppliers technical experts, we have chosen the materials best suited for our application.

The solvent can be sorbed on the magnetic particles by standard techniques used in the manufacture of chromatographic materials (4). We have tested different solvent compositions for effectiveness and efficiency in removing TRU elements from acidic nitrate solutions. The stability of the coatings is being evaluated by physical and chemical characterization. We have also verified that the magnetic properties of the particles can be used to remove them from the decontaminated solution.

A process will be developed to strip TRU elements from the particles using either aqueous-phase complexants or a three-step operation. In the latter option, the first step is removing the solvent from the particles by using an alcohol (or organic solvent), which dilutes the CMPO and lowers distribution ratios so that stripping will be facilitated. The second step is stripping the TRU elements by using an aqueous solution of dilute nitric acid, and the third step is resorbing the CMPO/TBP on the particles by evaporating the selected solvent.

Once the chemistry is understood, a laboratory demonstration of the entire process will be performed in a test bed. Initial tests have been performed with simulants, and later tests will be performed on actual dissolved sludge. Final demonstrations will be performed at Hanford under pilot-plant conditions. Out of the many tanks and waste compositions at Hanford, the MACS development effort is focusing primarily on the tanks of waste that originated from the PFP. This waste has very small concentrations of lanthanides (which are also extracted by CMPO and can cause solvent loading and therefore a low extractability of TRU elements) and is appropriate for treatment using the MACS process. Table 1 shows the non-TRU composition of these tanks.

\section{DISCLAIMER}

This report was prepared as an account of work sponsored by an agency of the United States Government. Neither the United States Government nor any agency thareof, nor any of their employees, makes any warranty, express or implied, or assumes any legal liability or responsibility for the accuracy, completeness, or usefulness of any information, apparatus, product, process disclosed, or represents that its use would not infringe privately of trade name, Irademark, ence herein to any specific commercial product, pross, or service by irade name, irademark, manufacturer, or otherwise does not necessarily constilute or inply its end any anereof. The views mendation, or favoring by the United States Covernment or any agency thereof and opinions of authors expressed herein do not 
Table 1. PFP Waste Simulant Composition

\begin{tabular}{ccc}
\hline Component & $\begin{array}{c}\text { Component } \\
\text { Charge }\end{array}$ & $\begin{array}{c}\text { Conc. } \\
\text { (mol/L) }\end{array}$ \\
\hline $\mathrm{H}$ & 1 & $1.5 \mathrm{E} 00$ \\
$\mathrm{Be}$ & 0 & $7.0 \mathrm{E}-05$ \\
$\mathrm{Na}$ & 1 & $4.0 \mathrm{E}-02$ \\
$\mathrm{Mg}$ & 2 & $6.0 \mathrm{E}-02$ \\
$\mathrm{Al}$ & 3 & $4.3 \mathrm{E}-01$ \\
$\mathrm{~K}$ & 1 & $3.0 \mathrm{E}-03$ \\
$\mathrm{Ca}$ & 2 & $6.0 \mathrm{E}-02$ \\
$\mathrm{Cr}$ & 3 & $4.0 \mathrm{E}-04$ \\
$\mathrm{Mn}$ & 2 & $3.0 \mathrm{E}-03$ \\
$\mathrm{Fe}$ & 3 & $3.0 \mathrm{E}-02$ \\
$\mathrm{Ni}$ & 2 & $8.0 \mathrm{E}-02$ \\
$\mathrm{Cu}$ & 2 & $3.0 \mathrm{E}-04$ \\
$\mathrm{Zn}$ & 2 & $6.0 \mathrm{E}-04$ \\
$\mathrm{~Pb}$ & 2 & $5.0 \mathrm{E}-04$ \\
$\mathrm{~F}$ & -1 & $9.0 \mathrm{E}-02$ \\
$\mathrm{SO}_{4}$ & -2 & $1.0 \mathrm{E}-02$ \\
$\mathrm{NO}_{3}$ & -1 & $3.05 \mathrm{E} 00$ \\
\hline
\end{tabular}

\section{EXPERIMENTAL}

\section{PARTICLE SELECTION}

The particle selection was determined by the following factors: 1) extractants sorption properties; 2) the magnetic characteristics of the particles for the sefaration; and 3) the particle morphology, determined by transmission electron microscopy (TEM). The first factor is determined by the MACS partition coefficient $\left(K_{d}=\right.$ activity in the solid phase /activity in the liquid phase). All three factors aided in evaluating the various commercial products.

\section{PARTICLE COATING}

The particles acquire their ferromagnetic properties from magnetite being incorporated in their structure. The paruc!es vary in size from 0.1 to $25 \mu \mathrm{m}$, and possess a wide range of shapes. The commercially purchased particles came with a passive coating (polymeric coating). The passive coating that demonstrated the most promise for CMPO/TBP adsorption was charcoal in a cross-linked N, N-methylene bis-acrylamide. As illustrated in Fig. 2, the TEM micrograph shows the large surface areas (irregular shape) of these magnetic particles: the dark areas represent crystalline magnetite particles, and the adjacent lighter areas contain the passive coating. The particles were washed with $0.02-\mu \mathrm{m}$-filtered water several times to eliminate preservatives and additives, then were dried and weighed. Then, $0.02-\mu \mathrm{m}$-filtered hexane or ethanol was used to disperse the particles and act as a volatile solvent for the coating. CMPO/TBP 
was added to the mixture and the particles were dispersed by an ultrasonic bath and finally dried in a rotoevaporator at $80-100^{\circ} \mathrm{C}$ until constant weight obtained. Active coating thicknesses were calculated and prepared with a wide range of CMPO/TBP concentrations tabulated in Table 2.

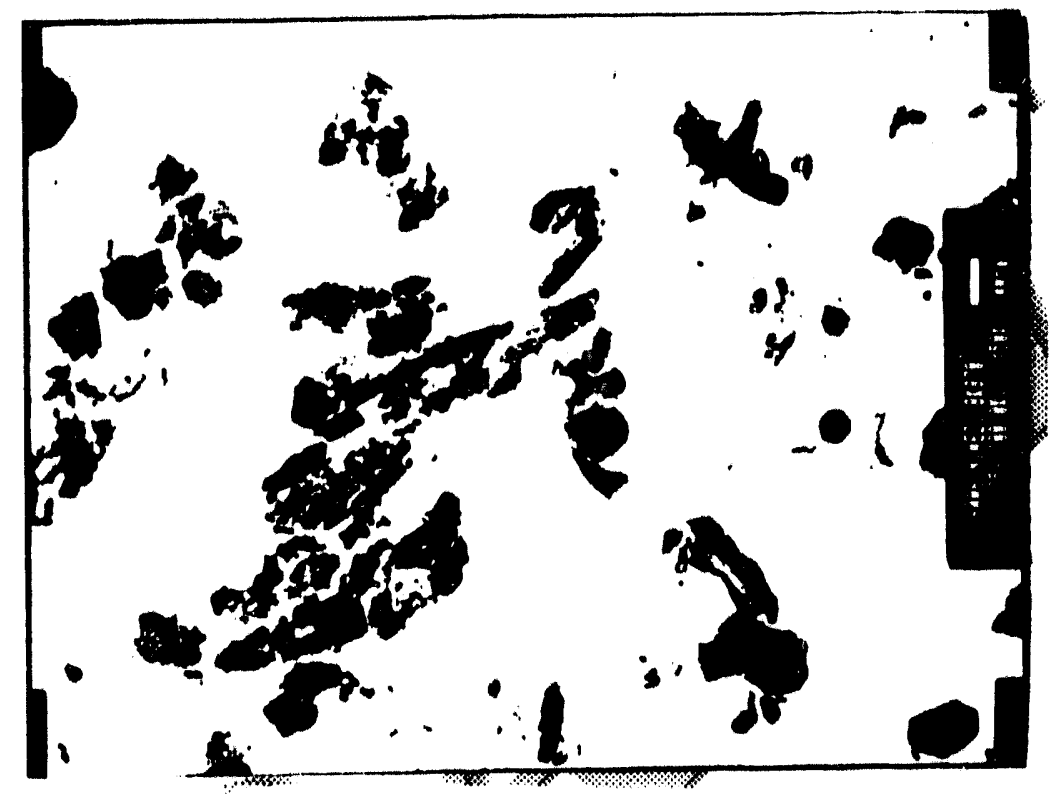

Fig. 2. TEM Micrograph of Magnetic Particles with Passive Coating

\section{EXTRACTION $\mathrm{K}_{\mathrm{d}}$}

Particle suspensions of approximately 1 wt\% or less were contacted with nitric acid solutions containing ${ }^{241} \mathrm{Am}$ or ${ }^{238} \mathrm{Pu}$. This low particle mass to solution ratio chosen allows the process to compete with more traditional separation techniques such as solvent extraction and ion exchange. The suspensions were held in a sonic cleaning bath to enhance the dispersion, placed in a temperature bath at $25^{\circ} \mathrm{C}$ for thermal equilibrium, and agitated with a vortex mixer to further disperse the solid suspension. This procedure was repeated two times, then the mixtures were centrifuged and placed in a rare-earth permanent magnet rack to cause separation. The supernatant was withdrawn from solution, and an aliquot was used for liquid scintillation $(238 \mathrm{Pu})$ or gamma counting $\left({ }^{241} \mathrm{Am}\right)$. Mass balance calculations were used to determine $\mathrm{K}_{\mathrm{d}}$ values. We expected to modify this extraction procedure for large-scale operation. 


\section{STRIPING $\mathrm{K}_{\mathrm{d}}$}

The radionuclide loaded magnetic particles were dried in preparation for stripping experiments. Fresh stripping agent was added and contacted following a procedure similar to that used in the extraction experiments. The volume of stripping agent was one-tenth the aqueous phase volume used for extraction experiments

\section{RESULTS AND DISCUSSION}

\section{EFFECTIVENESS OF SEPARATION}

\section{Coating Dependency}

To determine their effectiveness of TRU separation, the CMPO/TBP composition was fixed, and three samples of varying calculated thicknesses were formulated and tested. High CMPO concentrations were initially studied (at $2 \mathrm{M} \mathrm{HNO} 3$ with $241_{\mathrm{Am}}$ tracer) because the MACS technology is intended to be used for batch processing. The molar concentrations of CMPO were varied between 1 and $1.5 \mathrm{M}$ diluted in TBP. The partition coefficients $\left(K_{d}\right)$ are presented in Table 2.

Table 2. Dependency of $K_{d}$ on Coating Thickness and composition

\begin{tabular}{ccc}
\hline $\begin{array}{c}\text { CMPO } \\
(\mathrm{M})\end{array}$ & $\begin{array}{c}\text { Thickness } \\
{[\mu \mathrm{m}]}\end{array}$ & $\begin{array}{c}\mathrm{K}_{\mathrm{d}} \\
(\mathrm{g} / \mathrm{mL})\end{array}$ \\
\hline 1 & 0.6 & 827 \\
1 & 0.8 & 1395 \\
1 & 1 & 2471 \\
& & \\
1.36 & 1 & 497 \\
1.36 & 1.2 & 856 \\
1.36 & 1.4 & 1096 \\
& & \\
1.5 & 0.45 & 2832 \\
1.5 & 0.56 & 2401 \\
1.5 & 0.65 & 2660 \\
\hline
\end{tabular}

The 1.0 and 1.5M CMPO samples were prepared in hexane, while the $1.36 \mathrm{M}$ CMPO samples were coated by using ethanol as the carrier diluent. Both the 1.0 and $1.36 \mathrm{M}$ data sets follow the intuitively expected trend of increasing $\mathrm{K}_{\mathrm{d}}$ with increasing coating thickness. Figure 3 illustrates the variation of $\mathrm{K}_{\mathrm{d}}$ as a function of coating thickness for various CMPO 
concentrations. The trend shows that as the concentration of CMPO increases, the change in $\mathrm{K}_{\mathrm{d}}$ as a function of coating thickness decreases, if saturation or loading effects is negligible. For a CMPO concentration of $1.5 \mathrm{M}$, the curve reaches a plateau. This can be explained by high CMPO concentration reducing diffusion because of the high coating viscosity. Further increase in coating thicknesses is limited by particle adsorption capacity. All of the CMPO/TBP concentrations used in these experiments have given larger $\mathrm{K}_{\mathrm{d}}$ for $\mathrm{Am}$ and $\mathrm{Pu}$ than expected from CMPO concentration dependence (5)(e.g., TRUEX process). For plutonium extraction, this effect can be partially attributed to TBP extraction, while for americium, no TBP extraction effects are expected.

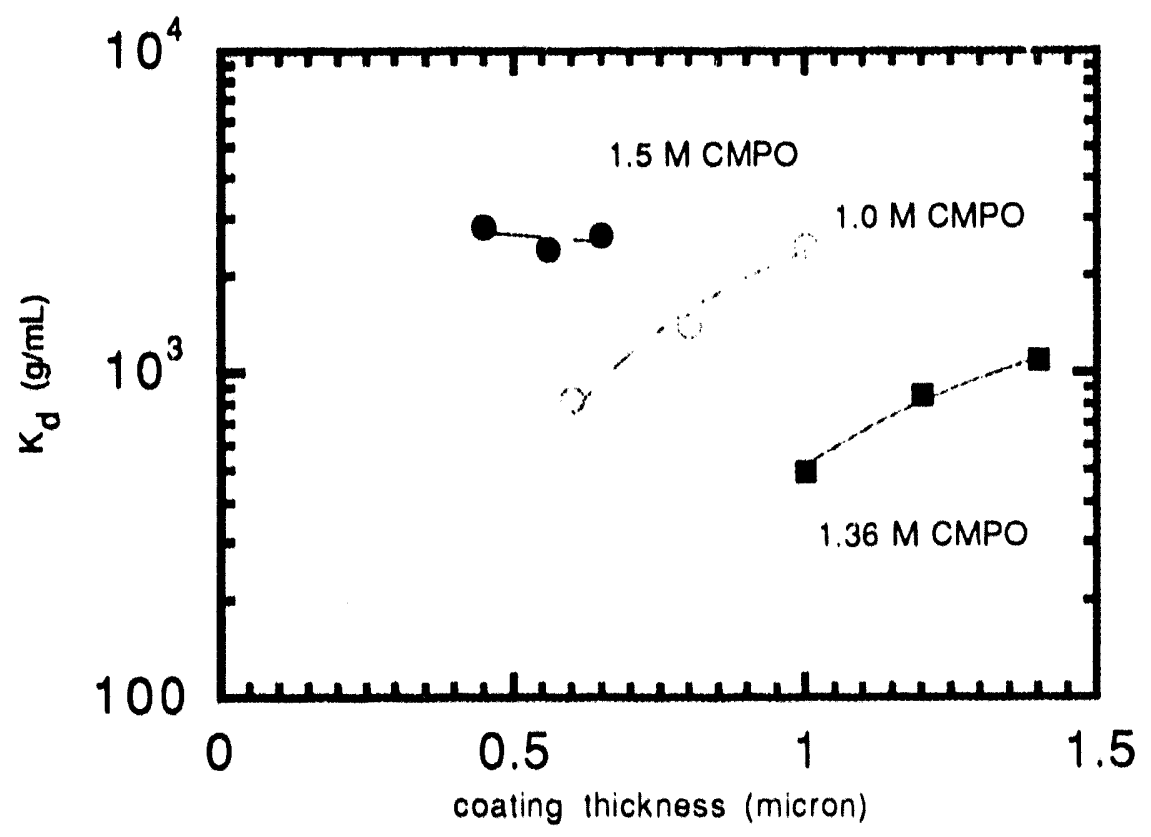

Fig. 3. Plot of Dependence of $K_{d}$ on Calculated Coating Thickness for ${ }^{241} \mathrm{Am}$

Since the volatile solvent should have completely evaporated during the coating process, $\mathrm{K}_{\mathrm{d}}$ should be independent of the solvent used. A comparison of the ethanol and the hexane data shows that the magnitude of the $\mathrm{K}_{\mathrm{d}}$ values for the $1.36 \mathrm{M}$ CMPO with ethanol fall outside the range observed for the 1.5 and 1.0M CMPO with hexane (Fig. 3). On the basis of recent coating analyses, this discrepancy may be due to differences in the $1.36 \mathrm{M}$ coating process. 


\section{Nitric Acid Dependency}

The nitric acid dependency of the MACS process is important for the application of this process to wastes having a wide range of acidities. The partition coefficients for various coatings were monitored using ${ }^{241} \mathrm{Am}$ and ${ }^{238} \mathrm{Pu}$ tracers. Samples were tested in $2 \mathrm{M}, 5 \mathrm{M}$ and $8 \mathrm{M}$ nitric acid with CMPO concentrations of 1.0 and $1.5 \mathrm{M}$. The results are presented in Fig 4 . With increased nitric acid concentrations, the $K_{d}$ values decreased for all the CMPO/TBP concentrations, as shown in Fig. 4.

Figure 4 shows that the four curves have similar shapes. 'I'he $\mathrm{K}_{\mathrm{d}}$ values for both $\mathrm{Am}$ and $\mathrm{Pu}$ decrease slowly over the entire range of nitric acid concentrations, but they all fall between 400 and 3000 for americium and between 3900 and 46,000 for plutonium. This result suggests that the process can be applied in a batch mode for a wide range of high nitric acid concentrations without a large loss in extraction capabilities.

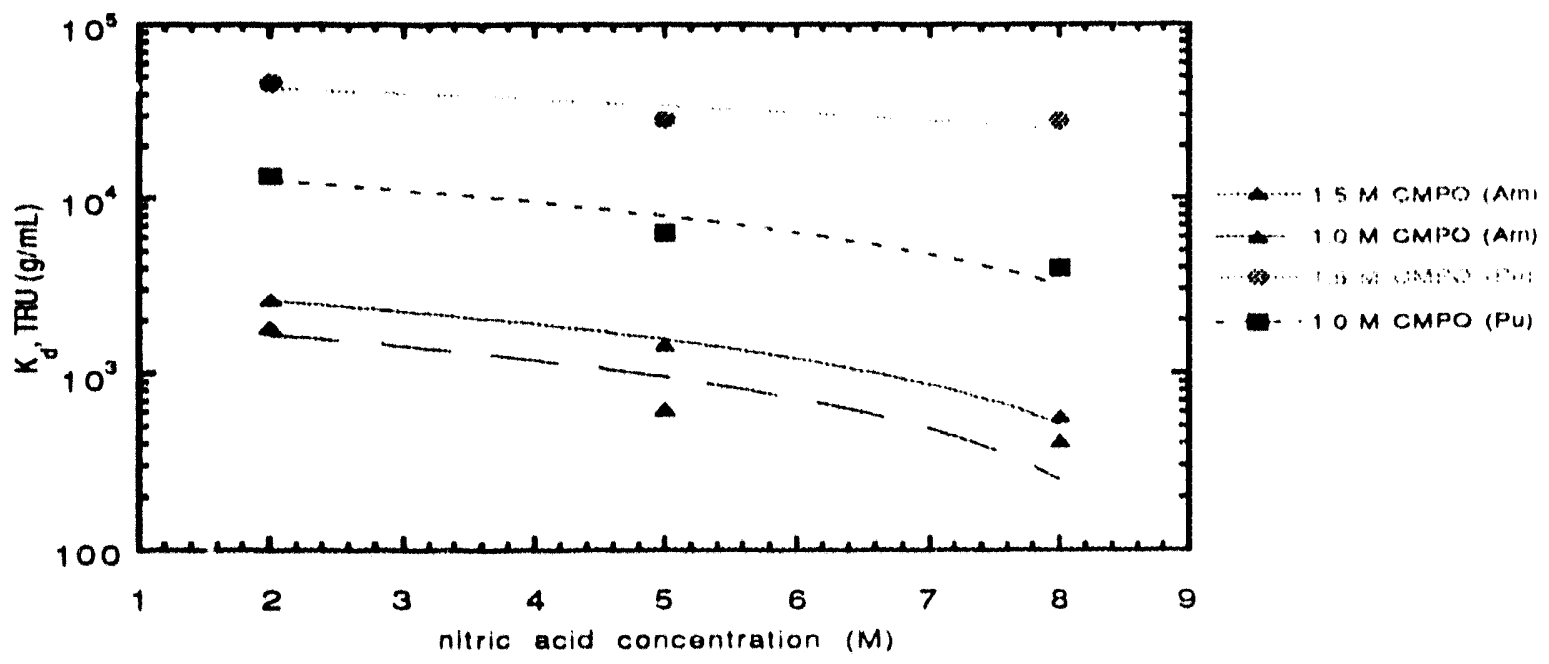

Fig. 4. $K_{d}$ Dependence on Nitric Acid Concentration for $241 \mathrm{Am}$ and $238 \mathrm{Pu}$ for CMPO/TBP Coatings on Magnetic Particles

We compared the two $K_{d}$ data sets for americium to the distribution ratio (D) derived from americium solvent extraction chemistry in TRUEX.NPH (normal paraffinic hydrocarbon). A smooth curve describing the $D$ values for americium in nitric acid solutions was generated from the Generic TRUEX Model (GTM) (5) for nitric acid concentrations between 1 and $8 \mathrm{M}$. Figure 5 
combines the data from the GTM with the data in Figure 4. The plot shows that americium follows the expected trends for the TRUEX process for the acid concentration range investigated.

In these experiments plutonium tencled to show slightly decreased $\mathrm{K}_{\mathrm{d}}$ with increased nitric acid concentration (Fig. 4). This trend disagrees with the distribution ratios obtained for plutonium by the GTM, where $\mathrm{D}_{\mathrm{Pu}}$ increases with increasing nitric acid concentrations.

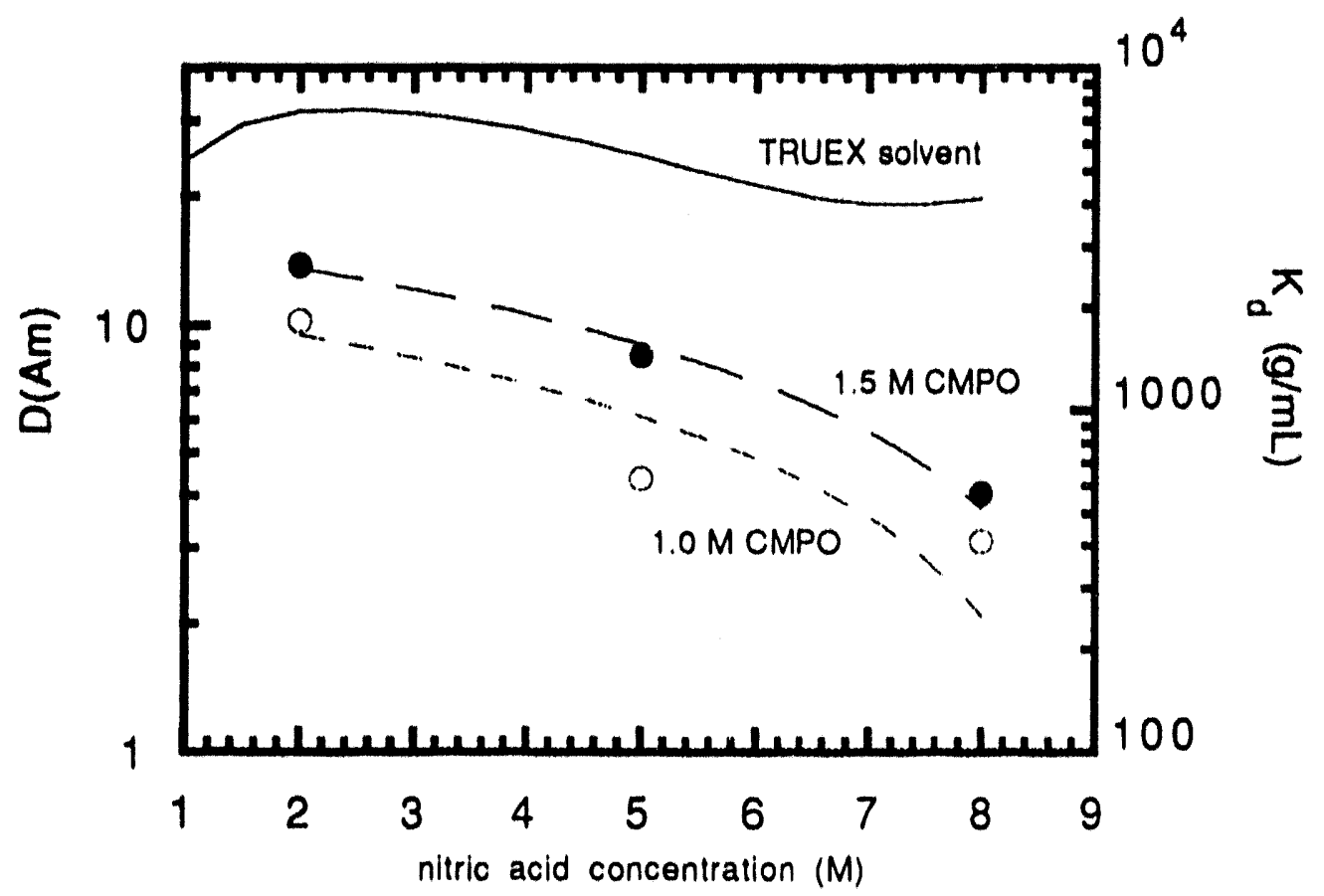

Fig. 5. Comparison of Americium Distribution Ratios in TRUEX Solvent and $\mathrm{K}_{\mathrm{d}}$ (for CMPO Coated sorbed Magnetic Particles in Nitric Acid Solutions

\section{STRIPPING $\mathrm{K}_{\mathrm{d}}$}

Because the $K_{d}$ values obtained using magnetic particles are quite large, an efficient recovery stage is required. The usual stripping process for nitrate waste streams involves the use of dilute nitric acid for americium and aqueous phase complexant or reducing agent for plutonium. However, because the MACS process results in large $\mathrm{K}_{\mathrm{d}}$ values due to the high concentration of CMPO, dilute nitric acid would be inefficient for stripping americium. A three step process for stripping is necessary. In the first step CMPO and TBP alone with the TRU elements are stripped from the particles by using a hydrocarbon or an alcohol. In the second step, 
the TRU are stripped from the organic phase, which is now a dilute CMPO solution, by an appropriate aqueous phase. In the third step the volatile hydrocarbon or alcohol is evaporated leaving the CMPO/TBP residual on the particle surface.

Table 3 gives the stripping $\mathrm{K}_{\mathrm{d}}$ values for plutonium. The values were derived from the mass balance equation (Eq. 1), with the assumption that there is negligible loss in particle mass before and after stripping:

$$
K_{d}^{\text {strip }}=\frac{\left[\left(\frac{g_{p}}{V}\right) K_{d}^{\text {ext }} C_{\text {final }}^{\text {ext }}-C_{\text {final }}^{\text {strip }}\right]}{\left(\frac{g_{p}}{V}\right) C_{\text {final }}^{\text {strip }}}
$$

Where $g_{p}$ is the mass of the particles; $V$ is the volume of waste solution; $C_{\text {final }}{ }^{\text {strip }}$ and $C_{\text {final }}$ ext are the final concentrations after stripping and extraction, respectively; and $\mathrm{K}_{\mathrm{d}}$ ext is the extraction partition coefficient.

Table 3. Stripping $\mathrm{K}_{\mathrm{d}}$ for ${ }^{238} \mathrm{Pu}$ in PFP Simulant

\begin{tabular}{cccc}
\hline Sample & $\begin{array}{c}\text { Stripping } \\
\text { Solvent }\end{array}$ & $\begin{array}{c}\mathrm{K}_{\mathrm{d}} \\
\text { Loading }\end{array}$ & $\begin{array}{c}\mathrm{K}_{\mathrm{d}} \\
\text { Stripping }\end{array}$ \\
\hline 1.2M CMPO & ethanol & 1913 & 4.47 \\
$1.0 \mathrm{M}$ CMPO & butyl alcohol & 3323 & 4.75 \\
$1.0 \mathrm{M}$ CMPO & ethanol & 1553 & 0.65 \\
\hline
\end{tabular}

These stripping tests showed a large reduction in $\mathrm{K}_{\mathrm{d}}$ values. Other stripping experiments gave negative $K_{d}$ stripping values, which qualitatively indicates that stripping efficiently removed the TRU elements and CMPO from the particles. The negative values, can be attributed to errors in the assumption in the mass balance equation. In addition, we were able to easily reduced the volume by a factor of 10 in many cases. Although the results in Table 3 are encouraging, much further study is needed. 
The $K_{d}$ values obtained for TRU material from the MACS process are large. Unfortunately, the waste streams from $m$. ny of the Hanford SSTs contain large concentrations of lanthanides and other elements that may compete with the extraction of americium. Lanthanide loading of the CMPO can occur, and difficulty in the TRU separation can be expected when lanthanide concentrations are high. If sludges from all the tanks are combined then an average waste composition (1) can be obtained (see Table 4). A high lanthanide concentration in the combined sludge could interfere with the in situ MACS processing.

Table 4. Composition of the Simulated Dissolved Sludge from all the Hanford SSTs

\begin{tabular}{cc}
\hline Component & $\begin{array}{c}\text { Conc. } \\
(\mathrm{mol} / \mathrm{L}) \mathrm{a}\end{array}$ \\
\hline $\mathrm{Fe}$ & $1.72 \mathrm{E}-01$ \\
$\mathrm{Na}$ & $7.08 \mathrm{E}-02$ \\
$\mathrm{Ca}$ & $4.91 \mathrm{E}-02$ \\
$\mathrm{M} \mathrm{n}$ & $4.29 \mathrm{E}-02$ \\
$\mathrm{Cr}$ & $3.77 \mathrm{E}-02$ \\
$\mathrm{Bi}$ & $1.79 \mathrm{E}-02$ \\
$\mathrm{Zr}$ & $1.30 \mathrm{E}-02$ \\
$\mathrm{Eu}$ & $9.67 \mathrm{E}-03$ \\
$\mathrm{Sr}$ & $6.53 \mathrm{E}-03$ \\
$\mathrm{Ag}$ & $5.61 \mathrm{E}-03$ \\
$\mathrm{Ba}$ & $5.32 \mathrm{E}-03$ \\
$\mathrm{Zn}$ & $2.46 \mathrm{E}-03$ \\
$\mathrm{Mg}$ & $1.58 \mathrm{E}-03$ \\
$\mathrm{Co}$ & $7.21 \mathrm{E}-04$ \\
$\mathrm{Cd}$ & $5.94 \mathrm{E}-04$ \\
$\mathrm{~Pb}$ & $5.21 \mathrm{E}-04$ \\
\hline
\end{tabular}

a Determined by Inductively Coupled Plasma analysis.

To monitor loading effects, we studied TRU separation from PFP and SST simulated waste solutions (characterized in Table 1 and Table 4, respectively) spiked with TRU tracer. Table 5 shows the values of $\mathrm{K}_{d}$ measured in the simulant solutions. For the PFP waste the average $K_{d}$ values for $\mathrm{Am}$ and $\mathrm{Pu}$ are close to 100 and 3000, respectively. Because the concentrations of lanthanides and other interfering elements are negligible, TRU elements can be separated from the PFP feed stream. For the SST waste, the TRU separation was initially performed with tracer levels of both ${ }^{241} \mathrm{Am}$ and ${ }^{238} \mathrm{Pu}$ and a lanthanide-to-plutonium ( $\mathrm{Ln} / \mathrm{Pu}$ ) ratio on the order of $10^{8}$. For these tests with the SST simulant, $K_{d}$ was 3 for plutonium in $0.75 \mathrm{M}$ CMPO/TBP and 200 for 
americium in $1 \mathrm{M}$ CMPO/TBP coating. The plutonium experiments were modified by adding sufficient plutonium to achieve a $\mathrm{Ln} / \mathrm{Pu}$ ratio of about 300 (the expected $\mathrm{Ln} / \mathrm{Pu}$ ratio in SST waste); much larger $K_{d}$ values for plutonium were achieved $\left(K_{d}=2400\right)$. Further studies are underway to determine the effects of $\mathrm{Ln} / \mathrm{Am}$ and $\mathrm{Ln} / \mathrm{Pu}$ ratios on $\mathrm{K}_{\mathrm{d}}$ values. The results obtained suggest that the MACS process can be applied to remediation problems at the Hanford Site and other sites where the waste streams have low concentrations of TRU elements. The MACS process has limitations at high concentrations of TRU and/or interfering elements. In such situations, more conventional solvent extraction or ion exchange techniques may be more applicable. 
Table 5. $\mathrm{K}_{\mathrm{d}}$ Measurements for Various Simulant/Tracer Solutions

\begin{tabular}{|c|c|c|c|}
\hline $\begin{array}{c}\text { [CMPO] } \\
\text { (M) }\end{array}$ & $\begin{array}{l}\text { Simulant } \\
\text { Solution }\end{array}$ & $\mathrm{K}_{d}$ & $\mathrm{Ln} / \mathrm{Pu}$ \\
\hline 0.75 & $241 A m-P F P$ & $1.05 E+02$ & $\div$ \\
\hline 0.75 & 238PU.PFP & $4.94 E+03$ & $*$ \\
\hline 0.75 & PU-SST & $3.00 E+00$ & $1.0 E 08$ \\
\hline 1 & 238PU-PFP & $3.32 E+03$ & * \\
\hline 1 & 238PU-PFP & $1.55 E+03$ & * \\
\hline 1 & 241Am-PFP & $2.08 E+02$ & * \\
\hline 1.2 & PU-SST & $2.43 E+03$ & $3.0 \mathrm{EO} 2$ \\
\hline
\end{tabular}

\section{MATERIAL STABILITY}

We are currently studying the effects of gamma irradiation on the separation capability of the particles under various acid conditions. As the particles are reused, they are exposed to additional doses from the TRU elements. We are using an ANL ${ }^{60} \mathrm{Co}$ source to examine the effects of low ( 10 cycles of use), medium ( 100 cycles) and high (1000 cycles) dose rates. By monitoring the $\mathrm{K}_{\mathrm{d}}$ measurements, particle damage, and efficiency of the magnetic separation stage, we can estimate the robustness of the process under actual waste conditions.

The degradation of extraction efficiency is affected by both the contacts with nitric acid and radiation dose. Since high doses measurements have longer contact times in acid solutions, it is difficult, with the limited data available, to determine how much of the degradation of particles is due solely to the gamma irradiation, and how much is due to the magnetite dissolution. Current activities are focused on distinguishing between these two effects and among other effects on material stability, such as dissolution of CMPO and TBP in solution.

\section{EFFECTIVENESS OF RECOVERY}

The separation of the magnetic particles from solution has been achieved efficiently using commercially available rare earth magnets, complete separation was usually achieved within minutes regardless of particle size. Settling problems due to particles without the magnetite core were confirmed by TEM studies and particles required pretreatment to minimize this effect.

The recovery of the particles depends on their magnetic properties such that any variation in the particles magnetic nature can effect the separation stage. The only condition that can strongly affect the magnetic properties is irradiation from TRU and other tank components. In order to quantify and determine the robustness of separation, magnetization measurements using a Superconducting QUantum Interference Device (SQUID) magnetometer was performed to 
determine the degradation of the magnetic particles by ${ }^{60} \mathrm{Co}$ gamma irradiation. Figure 6 shows a saturation in the magnetization of 1 Tesla for all particles tested. The variation of the magnitude of the magnetization was attributed to lack of accounting for the CMPO/TBP mass on the particles. The important feature of Figure 6 is the applied magnetic field in which the magnetization saturates showing that the effects of gamma irradiation are negligible on the magnetic properties and thus, on the magnetic separation stage.

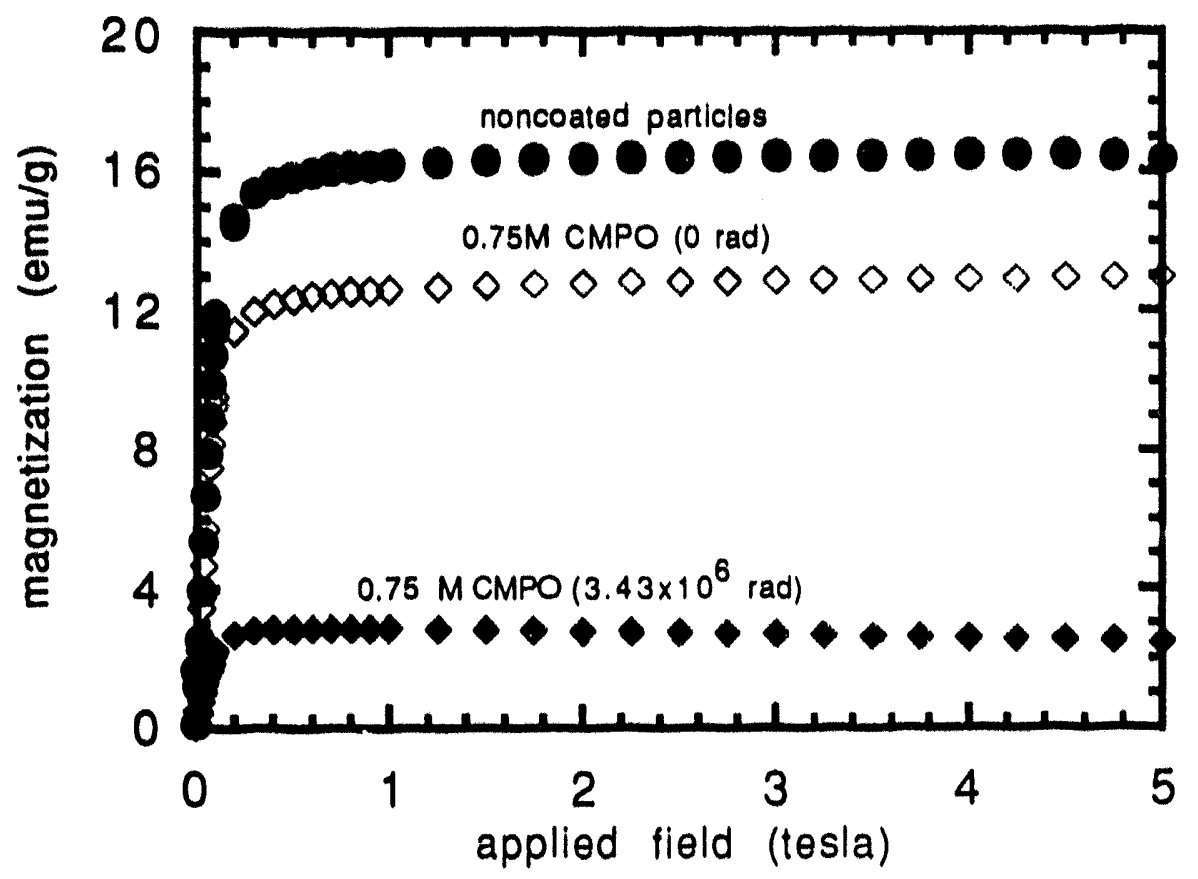

Fig. 6. ${ }^{60}$ Co Irradiation Effects on the Magnetic Properties of the MACS Particles

\section{CONCLUSION}

The development of the MACS process has shown that it is feasible to separate and strip TRU elements from acidic media. This compact process could be applied where installation space of complex ion-exchange and/or solvent extraction equipment is limited. The preliminary results of the $K_{d}$ measurements, magnetic characterization, and TEM studies indicate that the MACS process shows potential for use under real waste conditions. In continuing development activities we are working to optimize the coating factors for Hanford tank waste and other DOE applications. 
The authors would like to thank $H$. Diamond for providing the SST simulant, C. Bradley for the TEM micrographs, and U. Welp for the magnetic characterization. This work is supported by the U.S. Department of Energy under Efficient Separation Processes Integrated Program (ESPIP), Contract W-31-109-Eng-38. 


\section{REFERENCES}

1. J. L. Straalsund, J. L. Swanson, E. G. Baker, J. J. Holmes, E. O. Jones, W. L. Kuhn, "Clean Option: An Alternative Strategy for Hanford Tank Waste Remediation," PNL-8388, 1 (1992).

2. E. P. Horwitz, D. G. Kalina, H. Diamond, G. F. Vandegrift, and W. W. Schulz, "The TRUEX Process--A Process for the Extraction of the Transuranic Elements from Nitric Acid Wastes Utilizing Modified PUREX Solvent," Solvent Extr. Ion Exch. 3,75-109 (1985).

3. R. Leonard, G. F. Vandegrift, D. G. Kalina, D. F. Fisher, R. W. Bane, L. Burris, E. P. Horwitz, R. Chiarizia, and H. Diamond, "The Extraction and Recovery of Plutonium and Americium from Nitric Acid Waste Solutions by the TRUEX Process-..Continuing Development Studies", ANL-85/45 (1985).

4. E. P. Horwitz, M. L. Dietz, D. N. Nelson, J. J. LaRosa, and W. D. Fairnan, "Colicentration and Separation of Actinides from Urine using a Supported Bifunctional Organophosphorus Extractant," Radiochimica Chimica Acta. 238, 236 (1990).

5. H. No, D. G. Wygmans, D. B. Chamberlain, C. Conner, J. C. Hutter, C. Srinivasan, R. A. Leonard, L. Nunez, J. Sedlet, and G. F. Vandegrift, "Treatment of Aqueous Mixed Wastes Containing RCRA Metals," Mixed Waste Proceedings of the second International Symposium Baltimore, Maryland, August 17-20 (1993). 

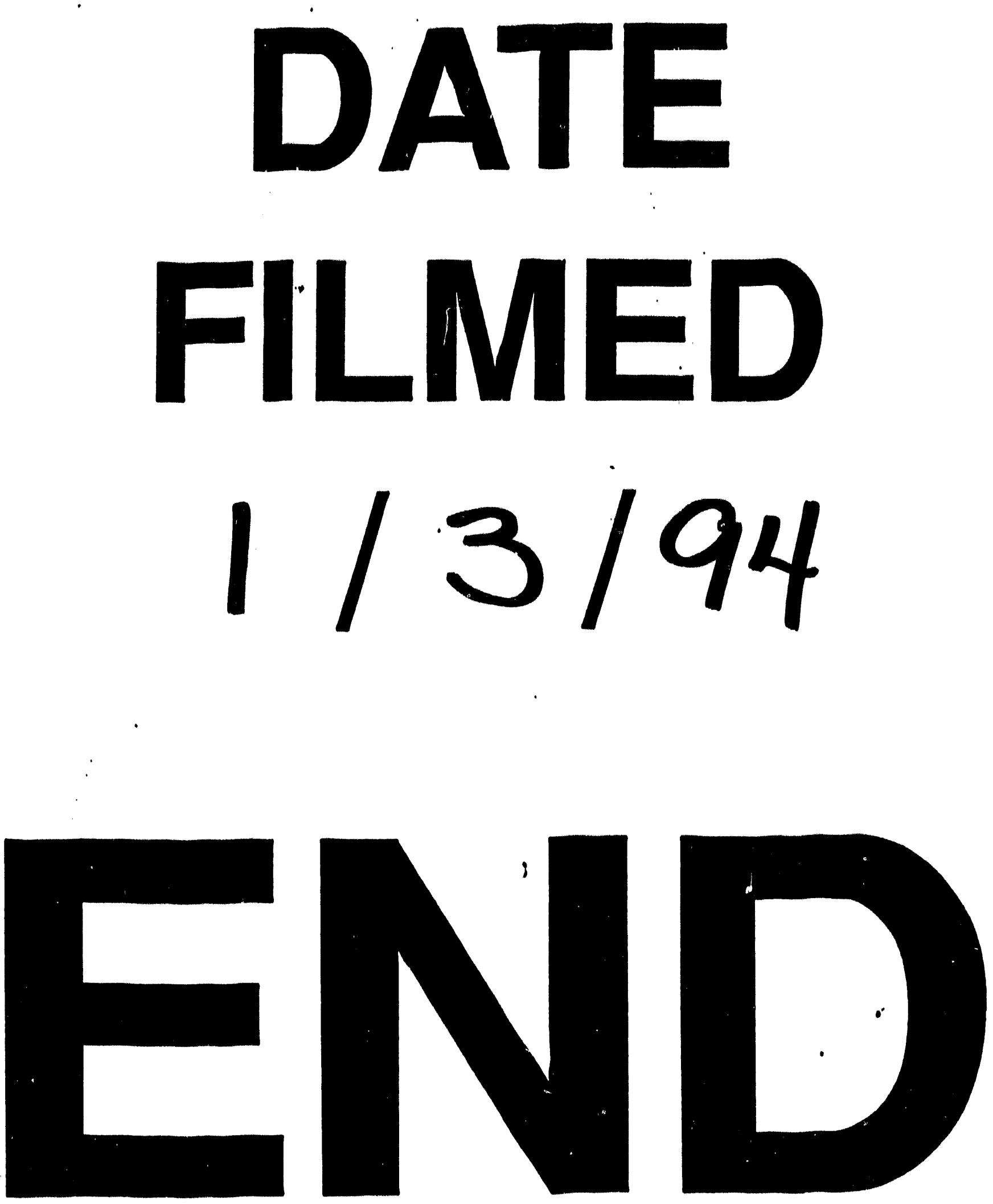
